\title{
Dimensões qualificadoras dos Programas de Transferência de Renda na América Latina e Caribe
}

\author{
Qualifying Dimensions of Income Transfer Programs in Latin America and the Caribbean
}

\author{
SALVIANA DE MARIA PASTOR SANTOS SOUSA*
}

\begin{abstract}
RESUMO - O presente artigo resulta de trabalho investigativo desenvolvido no contexto do Grupo de Avaliação e Estudo da Pobreza e das Políticas Direcionadas à Pobreza (GAEPP) da Universidade Federal do Maranhão. $O$ texto situa os programas de transferência de renda condicionada em contexto histórico da proteção social nessa parte do continente americano, contemplando reflexões sobre as principais dimensões que os qualificam: a família pobre como unidade básica de atenção; as condicionalidades como caminhos para favorecer a autonomia e a ruptura com a pobreza intergeracional; o território como espaço de focalização do atendimento; a racionalidade gerencial como paradigma do processo de gestão. Conclui-se que esses programas são uma face das recentes mudanças ocorridas no modo de regulação do capitalismo e que, embora sejam um lenitivo para os nomeados pobres, não representam mudanças importantes na configuração da pobreza e da desigualdade nos países que os adotam.
\end{abstract}

Palavras-chave - Pobreza. Proteção social. Capitalismo. Transferência de renda.

\begin{abstract}
This article is the result of investigative work developed in the context of the Poverty Assessment and Study Group and Policies Aimed to Poverty (GAEPP) of the Federal University of Maranhão. The text places the conditional cash transfer programs in historical context of social protection, in this part of the american continent, covering reflections on the key dimensions that qualify them: the poor family as the basic unit of attention; conditionalities as ways to promote autonomy and the break with intergenerational poverty; the territory as an area of focus of care; managerial rationality as the management process paradigm. Concludes that these programs are a face of the recent changes in the capitalist mode of regulation and that, although they are a solace for the poor named, do not represent major changes in poverty and inequality configuration in countries that adopt them.
\end{abstract}

Keywords - Poverty. Social protection. Capitalism. Cash transfer.

* Assistente Social, doutora em políticas públicas pela Universidade Federal do Maranhão (UFMA). Professora titular da Departamento de Serviço Social da Universidade Federal do Maranhão (UFMA), São Luís - MA/Brasil. CV: http://lattes.cnpq.br/8050800993055954. E-mail: politicaspublicasufma@gmail.com. Submetido em: julho/2015. Aprovado em: outubro/2015. 
presente artigo reflete sobre alguns aspectos resultantes da pesquisa intitulada "Programas de Transferência de Renda Condicionada na América Latina: estudo comparado - Bolsa Família (Brasil), Nuevo Régimen de Asignaciones Familiares - AFAM - P.E. (Uruguai) y Asignación Universal por Hijo para la Protección Social (Argentina)" realizada mediante cooperação acadêmica entre três países e cinco programas de pós-graduação ${ }^{1}$.

Nessa pesquisa foram identificadas dimensões que qualificam os Programas de Transferência de Renda Condicionada (PTRC) desenvolvidos na América Latina e Caribe, que já foram objeto de sistematização e análise em alguns textos, entre os quais se destacam Silva (2014) e Silva (2014a).

As reflexões aqui desenvolvidas, portanto, retomam as dimensões qualificadoras que consideramos mais relevantes desses programas, quais sejam: a família pobre como unidade básica de atenção; as condicionalidades como caminhos para favorecer a autonomia e a ruptura com a pobreza intergeracional; o território como espaço de focalização do atendimento; a racionalidade gerencial como paradigma do processo de gestão.

A análise sobre PTRC remete à compreensão das formas de proteção social construídas historicamente. Para Giovanni (1998), elas resultam de relações que se estabelecem entre os diferentes sujeitos sociais e que, em função de demandas construídas e lutas desenvolvidas, adquirem contornos diferenciados. Na sua formatação, podem ser identificados critérios de alocação de recursos de poder, não necessariamente excludentes: a tradição, a troca e autoridade.

Nesse sentido, as políticas que constituem os núcleos dos chamados "Sistemas de Proteção Social" reconhecidos no ocidente apresentam configurações particulares e respondem a direitos conquistados e institucionalizados nessa parte do mundo.

De acordo com Bobbio (1992a), a conquista de direitos foi um processo que teria se iniciado no debate filosófico, prosseguiu, com a passagem do discurso à prática, em que os direitos do homem abstrato foram transpostos para o cidadão, o homem concreto. Com sua materialização na Declaração Universal dos Direitos do Homem de 1948, passaram a ser não só positivos (regulados e protegidos), mas também universalizados e reconhecidos. Nesse sentido, embora espelhem a hegemonia da cultura ocidental, tais direitos tanto definem um mínimo ético que baliza a convivência entre os povos, como servem à configuração dos atuais Sistemas de Proteção Social. Nesse contexto, é relevante a mediação do Estado, que passa a assumir uma série de funções, inclusive a de criação de condições para prevenir riscos sociais resultantes das contingências da vida e do trabalho.

Viana e Machado (2008) reforçam a importância histórica desse debate ao afirmarem que

Os modernos sistemas de proteção social no século XX surgiram para atenuar as diferenças sociais criadas pelo livre funcionamento dos mercados e causa da produção de desigualdades. (...) A forma criada para proteger os cidadãos desses movimentos de produção de desigualdades e de insegurança social foi a assunção pelo Estado, principalmente após a Segunda Guerra Mundial, do financiamento e provisão de um grande número de bens e serviços que os cidadãos não poderiam acessar única e exclusivamente pela renda obtida pelo trabalho, ou quando sem trabalho necessitassem desses bens (VIANA; MACHADO, 2008, p. 647).

Há uma vasta literatura disponível ${ }^{2}$ que identifica na contemporaneidade dois modelos básicos de proteção social nos limites do capitalismo, os quais assumem visibilidade diretamente articulados ao movimento do capital e aos projetos nacionais. O primeiro é baseado na lógica do seguro, guarda relação com o direito contratual, sendo os benefícios, como aposentadorias e pensões, definidos a partir de contribuições individuais e de maneira facultativa. A distribuição das prestações é feita de forma padronizada, automática e imparcial, com base em direitos e deveres precisos (prêmios e contribuições), segundo modalidades institucionais particularizadas e centralizadas. Como decorre de contrato, nesse 
modelo ocorre uma exclusão automática de parte da população sem condições de arcar com o pagamento das prestações.

No segundo modelo denominado por alguns de "Seguridade Social" (FLEURY, 2010), a proteção social tem suporte no paradigma da solidariedade sistêmica, as medidas protetivas são orientadas pelos princípios da necessidade e do pertencimento à nação e os benefícios concedidos com a mediação do Estado têm fulcro em direitos reconhecidos e regulamentados.

Nos dois modelos, o trabalho possui centralidade. No primeiro caso, como garantia de recursos para custear o pagamento de seguro. No segundo, como arrimo para possibilitar aos agentes econômicos a conformação do Fundo Público que subsidia as ações de proteção. Porém, como se tratam de modelos ideais de relacionamento social, adequam-se às particularidades das sociedades que os acolhem. Nesse sentido, cabem intervenções de caráter condicional e discricionário para garantir o suprimento de necessidades individuais ou de categorias populacionais específicas. Tais intervenções compõem o amplo e polêmico campo da Assistência Social.

Nos 1940-1970, nos países situados nos marcos do capitalismo, criaram-se as condições que possibilitaram a materialização do modelo de seguridade social. De fato, uma vez que esse modelo é fundamentado na ideia de direitos e nos princípios de justiça e solidariedade intercalasses, é compatível com o pacto social democrata base da forma de regulação fordista-keynesiana, que corresponde a esse período histórico denominado de "30 anos gloriosos do capitalismo". Porém, na América Latina e Caribe, onde os sistemas de proteção social foram organizados a partir das décadas de 1920/1930, o modelo prevalecente resultou da articulação entre o padrão de seguro e formas de assistência social institucionalizadas pelo Estado.

Discutindo sobre o tema, Boschetti (2014) lembra que as determinações estruturais da economia capitalista tornaram os países da América Latina e Caribe incapazes de absorver a força de trabalho disponível na região. Nesse sentido, sem a contribuição necessária dos agentes econômicos para materializar o modelo de seguridade social, a assistência social sempre se constituiu como uma solução complementar à renda (adquirida, muitas vezes, na informalidade) ou uma alternativa nos casos de carência absoluta.

A partir dos anos 1980, com a nova crise sistêmica que se instalou no contexto capitalista, a questão social passou a ser definida pelos ideólogos do sistema e amplamente divulgada de forma reducionista, como pobreza. E a maneira privilegiada para lidar com as ameaças à ordem social decorrentes da pobreza atual e ainda impedir o aumento desse problema no futuro foi direcionar recursos para a população mais pobre mediante a provisão de serviços sociais e oferta de programas assistenciais. Os denominados PTRC serviriam, assim, a esse duplo objetivo, compondo uma geração de políticas assistenciais adotadas na América Latina e Caribe ${ }^{3}$.

No presente artigo, comungando com Silva (2014), os PTRC são tratados como parte de uma agenda de reformas orquestrada por organismos internacionais e que se materializaram em países da América Latina e Caribe com o propósito de desonerar os governos de compromissos postos pelo pacto social-democrata. Tal agenda comporta privatizações; descentralização, na forma de deslocamento dos recursos públicos para o financiamento das atividades em nível local, introdução de formas alternativas de produção e de operação dos serviços; e focalização, em contraposição à universalização, portanto, no sentido do redirecionamento de recursos a grupos específicos.

Sua concretização, nesses países, comporta: distribuição direta de recursos por meio de tecnologias como cartões magnéticos, com o propósito de obstar a intermediação de políticos e de burocracias públicas; utilização do setor privado como parceiro na provisão dos serviços; estimulo à participação local no processo de gestão; efetivação dos procedimentos de monitoramento e avaliação no sentido do uso mais eficiente dos recursos disponíveis. 


\section{Dimensões qualificadoras dos PTRC na América Latina e Caribe}

Há certo consenso entre estudiosos do tema ${ }^{4}$ de que o agravamento da miséria e da pobreza na América Latina e Caribe decorre de duas décadas (1980 e 1990) de programas de estabilização e ajuste estrutural orquestrados por países do centro capitalista, referenciados no Consenso de Washington 5 . Oliveira (2007) lembra que tal processo foi seguido, naqueles países, também pela dissolução da esfera pública, com a dificuldade de o Estado recuperar o controle legal da violência, uma das características do Estado Democrático de Direito.

Mesmo que uma fortíssima repressão, uma militarização total dê a impressão de recuperação do controle legal da violência pelo Estado, a essência do monopólio legal da violência, como lembra Wanderley Guilherme dos Santos, é que a lei deve controlar a violência à distância, sem a presença da polícia ou de forças similares: é esta a diferença crucial do Estado Democrático de Direito (OLIVEIRA, 2007, p. 13).

Desse modo, com a ausência de política há privilegiamento das formas gerencialistas de tratar a questão social.

É importante recordar que frente ao aumento da pobreza ${ }^{6}$ na América Latina e no Caribe, a partir dos anos 1990 (44\% da população encontrava-se em situação de pobreza, o que representava 220 milhões de pessoas, segundo dados publicados por Lima, Reis, Arregui e Tripiana (2014), a Comissão Econômica para a América Latina e o Caribe (CEPAL) apontava a necessidade de resgatar a essência do pacto social democrata com o fortalecimento de políticas públicas universais. Porém, tal indicação, que não foi acolhida pelos países da região, seria um contraponto às proposições de feição neoliberal, cuja tese relacionava o aumento da pobreza com problemas de governança (MARQUES, 2013).

A aliança com as teses neoliberais resultou na instituição de uma nova geração de políticas sociais, com foco no combate à pobreza e à miséria, de caráter abrangente, em termos do número de pessoas atendidas; são as PTRC. De acordo com Lima, Reis, Arregui e Tripiana (2014), esses programas associados ao aumento do piso salarial e algumas mudanças positivas ocorridas no mercado de trabalho provocaram uma redução da pobreza e da indigência em países da América Latina e Caribe (de 42\%, em 2004, para $28,8 \%$, em 2012). Os autores alertam, porém, que essa região continua sendo uma das mais pobres e desiguais do mundo, perdendo apenas para a África Subsaariana.

Os PTRC apresentam similaridade, pelo menos, no que diz respeito a quatro dimensões que os qualificam e consideradas como referência no presente artigo: a família pobre como unidade básica de atenção; as condicionalidades como caminhos para favorecer a autonomia e a ruptura com a pobreza intergeracional; o território como espaço de focalização do atendimento; a racionalidade gerencial como paradigma do processo de gestão.

\section{A família pobre como unidade básica de atenção}

Na configuração de políticas sociais, particularmente dos PTRC, há um ponto em comum: seu propósito é reduzir a pobreza e aumentar o nível de bem-estar das famílias. Porém, como não há consenso entre estudiosos quanto ao conceito de pobreza, essa indecisão se expressa na definição sobre o número efetivo de pobres em formações sociais concretas.

De fato, é importante lembrar que a pobreza, tanto no debate acadêmico quanto no discurso dos governos, apresenta diferentes interpretações. A concepção multidimensional acolhida na justificativa desses PTRC considera que não se pode reduzir pobreza às privações materiais, portanto deve-se considerar diferentes dimensões da vida que interferem na reprodução social dos trabalhadores e de suas 
famílias, como a dimensão cultural e a relacional. Pochmann (2004) interroga: Qual a medida da pobreza? Quem são os pobres, os muito pobres ou pouco pobres? São desempregados, vulneráveis, excluídos? Santana (2007) relembra as dificuldades dos que vivem em pequenos e inadequados espaços habitacionais.

A moradia em cortiços, palafitas e prédios abandonados, sob perigo de desmoronamento e em áreas de risco, a falta ou precariedade dos equipamentos e serviços coletivos urbanos e áreas periféricas, as lutas sociais pelo uso da terra. (...). Em pequenos e precários espaços, avessos à reunião de condições adequadas à vida urbana e à proteção da vida privada e da intimidade familiar (...) (SANTANA, 2007, p. 65-68).

Telles (2007) recorda que, além dos reconhecidamente destituídos de condições materiais de existência, há grande quantidade de "invisíveis" e, portanto, tendencialmente desconsiderados no processo gestionário das políticas públicas, caso dos explorados em trabalhos desenvolvidos em domicílio reavivado por redes nacionais e internacionais de subcontratação e os que vivem do trabalho autônomo que sustenta o comércio clandestino de produtos lícitos e ilícitos.

Da mesma forma pode-se questionar: o que constitui um nível de vida minimamente aceitável, capaz de provocar bem-estar de indivíduos, famílias ou populações?

Para estabelecer certo consenso sobre o tema, como em outros programas governamentais, em todos os PTRC analisados no contexto da pesquisa que dá suporte a esse artigo, a unidade básica de atenção é a família e a composição dos grupos denominados pobres é baseada na renda familiar per capita definida com base no conceito de linha de pobreza ${ }^{7}$. Esse conceito é empregado para delinear o nível de renda mínimo que um indivíduo ou família deve possuir para acessar os recursos indispensáveis para viver, portanto serve de parâmetro para definir os pobres que devem ser contemplados nos programas.

Entre os denominados pobres, Silva (2014a, p. 5) refere que os públicos preferenciais contemplados pelos PTRC são "crianças, idosos, desempregados, mulheres grávidas ou em amamentação e pessoas com deficiências". Também são encontrados outros públicos compostos por "indígenas, populações desalojadas por situação emergencial ou expulsas por conflitos, famílias quilombolas, população de rua e famílias com crianças em situação de trabalho infantil e escravo". Mas, continua a autora, a grande maioria dos programas se refere a famílias e não a indivíduos como seu público-alvo, tanto que os procedimentos de seleção utilizados são "varáveis relacionadas com as condições econômicas das famílias, com destaque à renda".

A análise dessa dimensão comporta duas premissas básicas. A primeira se refere à forma de inclusão dos beneficiários. O propósito desses programas, em geral, é ampliar o consumo das famílias, favorecer a criação de alternativas de trabalho, reduzir o trabalho infantil e aumentar o poder das mulheres. Fundamentalmente, porém, identificável nas análises feitas é o aumento do consumo, sobretudo, de produtos como alimentos e vestuário de crianças, além de certo aumento da autonomia da mulher que, na condição de receptora dos recursos monetários, passa a ter algum controle sobre a vida doméstica e o consumo da família, o que contribui para ampliação da sua autoestima. Trata-se do tensionado conceito de empoderamento.

Esses elementos indicam que a inclusão pela via dos PTRC não alcança o beneficiário como cidadão de direitos, nem como trabalhador, mas como consumidor. Da mesma forma que em outros programas dessa natureza, não é a inclusão expressa pela Carteira de Trabalho que se obtém, mas por meio de documentos como Cadastro da Pessoa Física (CPF) "que habilita o indivíduo a entrar de cabeça erguida numa instituição bancária "ainda que seja um banco dos pobres" ${ }^{8}$ (VIANA, 2008, p. 149).

A segunda premissa se refere ao privilegiamento da família como unidade de atendimento, o que representa uma forma de deslocamento de conflitos para o âmbito do privado, das relações intrafamiliares e comunitárias. Esse reforço da importância da vida doméstica e familiar importa, de alguma forma, 
concordar com o declínio da ideia da res pública. Recorde-se que esse conceito se refere não a uma agregação qualquer de pessoas articuladas por liames jurídicos, mas de vínculos societários que se pautam pelo espírito de comunidade, em que o poder, materializado na figura do Estado Moderno, está a serviço do público.

Nesse sentido, a opção pela unidade familiar como foco de atendimento, como lembram Couto, Yazbek, Silva, e Raichelis (2014), por um lado pode representar um avanço no sentido de não isolar o indivíduo das suas relações sociais; por outro, porém, pode favorecer a reprodução de uma visão conservadora em que essa instituição é entendida como unidade desvinculada do seu contexto sóciohistórico, portanto despolitizada. É o caso de discursos como os que tratam de "famílias desestruturadas e incapazes de aproveitar as oportunidades que lhe são oferecidas pela sociedade (e também pelo Estado) para resolverem seus problemas com seus próprios recursos" (COUTO, YAZBEK, SILVA; RAICHELIS 2014, p. 79).

\section{As condicionalidades como caminhos para favorecer a autonomia e a ruptura com a pobreza intergeracional}

Condicionalidades, parte da estrutura dos PTRC na América Latina e Caribe, constituem-se em contrapartidas exigidas das famílias a serem beneficiadas com os recursos transferidos, mas também demandam responsabilidades por parte dos governos, entre as quais a administração de todo o processo da política e a garantia de serviços complementares. Silva (2014a, p. 98) lembra que alguns países desenvolvem programas de transferência de renda para pessoas idosas (República Dominicana, Equador, Honduras, Jamaica, México, Paraguai e Peru), outros para pessoas com deficiência (Argentina, Equador, Jamaica e Paraguai) e outros, ainda, para adultos pobres em idade de trabalhar (Jamaica), geralmente sem condicionalidades.

As condicionalidades são configuradas como inovação em relação ao assistencialismo tradicional, uma vez que devem funcionar como mecanismos de empoderamento, autonomização e rompimento com a pobreza intergeracional.

De fato, o pressuposto que norteia esses programas é que a garantia de renda e o estímulo de inserção produtiva dos indivíduos e famílias no mercado de trabalho resultariam em autonomização e redução da pobreza atual, com reforço do acesso aos direitos sociais básicos nas áreas de educação, saúde e assistência social. Entretanto, seu principal objetivo é que o cumprimento dessas condições, associado a ações e programas complementares, em última instância, contribua para romper com a denominada pobreza intergeracional. Seu fundamento teórico, portanto, é a teoria do capital humano, que considera os atributos individuais, fortalecidos com ações deliberadas em educação e treinamento, como mediadores basilares para a inserção no mercado de trabalho. "A pobreza seria, assim, uma situação em que as pessoas se encontram por falta de determinados dotes que uma vez adquiridos os capacitam a pular a linha de pobreza" (VIANA, 2008, p. 148).

Nos programas investigados, a seleção dos beneficiários é feita por meio da análise de dados coletados, inclusive sobre a vida privada dos demandantes, para comprovação de pobreza, os chamados testes de meios. E, tanto a seleção dos beneficiários como a transferência de recursos e o acompanhamento das condicionalidades são procedimentos administrativos realizados com a utilização de modernos sistemas de informação e comunicação. Em caso do descumprimento desses compromissos por parte dos beneficiários são previstas sanções como advertência, suspensão e desligamento do programa. Porém, como lembra Silva (2014a) não é dada igual ênfase aos limites dos programas relacionados com os compromissos assumidos pelo governo, como razões para o descumprimento das condicionalidades pelas famílias. 
A grande maioria dos programas analisados considera duas razões básicas para suspensão e desligamento dos beneficiários: a perda das condições de elegibilidade e o descumprimento das condicionalidades, embora, como afirma Silva $(2014$, 2014a) alguns concedam um espaço temporal para permanência ou destaquem processos de revisão periódica ou contínua. Esse controle acentuado é justificado como uma maneira de direcionar o foco dos programas aos que, de fato, se constituem seus beneficiários potenciais.

Para autores como Pereira (2009), porém, formas controladoras de tratar os que demandam esse tipo de benefício constitui-se em negação de direitos de cidadania, uma vez que têm fulcro em anacronismos e constrangimentos, caso dos testes de meios e da fraudemania (mania de fraude em relação aos pobres). Para esses analistas, seriam um reforço da abdicação ao princípio da universalidade que tem suporte na ideia de direitos de cidadania, portanto de pertencimento à nação.

A perspectiva de proteção social que se delineia nesses programas, ao cumprir o propósito de combinar transferências monetárias e condicionalidades por meio de políticas fragmentadas, apenas alivia a pobreza da população atendida. Apresenta-se, pois, divorciada da garantia de direitos, da perspectiva de cidadania.

\section{O território como espaço de focalização do atendimento}

O conceito de território faz parte da configuração de todos os PTRC analisados. Conforme as normativas dos programas, as equipes devem levar em conta espaços geográficos circunscritos para seleção e acompanhamento das famílias demandantes.

Silva (2014a) refere-se ao uso de critérios geográficos como baliza para a seleção dos beneficiários em todos esses programas. É o caso do Programa Nuevo Régimen de Asignaciones Familiares, - AFAM P.E (Uruguai) que busca criar e manter espaços de educação direcionados a jovens e adultos, contemplando ações socioeducativas destinadas a fomentar e fortalecer a educação para o trabalho, em territórios determinados. Também do Programa Asignación Universal por Hijo- AUH (Argentina) que aborda a equidade territorial e o fortalecimento das famílias como meios para alcançar a máxima satisfação.

Essa dimensão geográfica tomada como referência dos PTRC refere-se ao "espaço habitado", síntese de relações sociais, portanto, fruto da interação entre sujeitos sociais diversos no cotidiano. Tratase de uma construção que reconhece a mediação de fatores sociais, econômicos, políticos e culturais que induzem segmentos sociais e famílias a situações de vulnerabilidade e risco social. O território não é, portanto, somente um pedaço particular de chão, mas uma localidade marcada pelas pessoas que ali vivem.

Harvey $(2004 ; 2011)$ refere-se à ressignificação da dimensão espacial, na condição de território, como uma estratégica acentuada no atual contexto histórico para a criação de condições da acumulação capitalista. O próprio "jogo estratégico local”, como lembra Santos (2002, p. 347), decorre de uma complexa dinâmica de organização do território, na qual as relações de força e os conflitos de interesses guiam comportamentos. Oliveira $(2007$, p. 29) advoga que se vive na contemporaneidade um processo de privatização, no sentido arendtiano, uma vez que os indivíduos são impelidos aos seus espaços privados, à insegurança decorrente da "privação" do espaço público e da alteridade.

Couto, Yazbek, Silva, e Raichelis (2014), consideram relevante a dimensão territorial incorporada pelas políticas públicas, porém apontam questões que podem ser consideradas relevantes para a análise dos PTRC. A primeira é a possibilidade de se reforçarem territórios homogêneos de pobreza, acentuando marcas e imagens negativas em relação aos espaços habitados e aos seus moradores. A segunda é de, na atual cartografia social das cidades que separa as pessoas e grupos por muros e tecnologias de segurança, 
seja reforçado um padrão de segregação espacial com acessos diferenciados à informação, à diversidade de oportunidades e aos equipamentos e bens públicos.

Finalmente, referindo-se à realidade brasileira, uma reflexão que pode ser estendida aos países latino-americanos e caribenhos, Couto, Yazbek e Raichelis (2014), relembram que parcela significativa dos males que compõem o quadro das vulnerabilidades sociais dos usuários situados no campo da Política de Assistência Social tem raízes estruturais, quais sejam: desvinculação entre políticas econômicas e sociais, precarização e insegurança do trabalho, enfraquecimento das instituições de proteção social, retraimento do Estado e das políticas públicas, incerteza e insuficiência do orçamento para a proteção social, baixa cobertura dos programas, serviços e benefícios (COUTO, YAZBEK e RAICHELIS, 2014).

\section{A racionalidade gerencial como balizadora do processo de gestão ${ }^{9}$}

Foucault (1982) desenvolveu um instigante trabalho sobre o que denomina governamentalidade. Para ele, governar é a arte de exercer o poder segundo o modelo da economia, que, a partir do século XVIII, passa a designar um nível da realidade, um campo de intervenção. É gerir a vida das pessoas em sua relação com as riquezas, os recursos, os meios de subsistência, o território e a relação com os problemas populacionais. Nessa composição, a família passa a ter uma dimensão instrumental, já que o objetivo explícito do governo é melhorar a sorte da população, aumentar sua riqueza, sua duração de vida e sua saúde.

Para autores como Bobbio (1992), do ponto de vista histórico, o Estado e sua expressão material, o governo, apresentam movimentos de restrição e alargamento do seu espaço de atuação. Tais movimentos ora privilegiam o espaço público, ora o espaço privado. O primeiro é orientado pela perspectiva de preservação dos interesses individuais e resulta na limitação das ações estatais. O primado do público, por sua vez, é norteado pela subordinação dos interesses privados aos da coletividade, com a ampliação do campo de defesa da igualdade substantiva e da solidariedade.

Para o mesmo pensador, tem havido, modernamente, uma tendência à aproximação entre esses dois espaços, acontecendo processos que ele denomina de privatização do espaço público (o setor privado serve-se do espaço público para alcançar objetivos particulares) e publicização do espaço privado (movimento do Estado na regulação do mercado e da vida privada, influenciando na justiça comutativa). Nessa perspectiva, o princípio que é hegemônico em determinado contexto sócio-histórico dá forma ao tipo de racionalidade que orienta a gestão das políticas públicas.

A operacionalização das políticas públicas desvela, assim, a capacidade de o governo entranhar-se na sociedade, de concentrar ou descentralizar as decisões necessárias à consecução dos resultados preconizados. Revela, também, a capacidade de negociação para resolução de, pelo menos, três dilemas básicos: a definição de critérios que tornam possível distinguir as necessidades merecedoras de satisfação; a opção por grupos ou comunidades a serem privilegiados com o repasse de recursos públicos em contextos específicos e a explicação ao restante dos partícipes da comunidade porque esses, e não outros grupos ou necessidades, foram privilegiados (SOUSA, 2007).

Há, segundo Paoli (2007), no atual contexto histórico, na configuração do processo de gestão da coisa pública, uma disputa pela eficiência entre os vários programas, louvando-se uma cidadania não política, baseada em uma espécie de racionalidade gerencial. O processo de gestão dos PTRC guarda compatibilidade com essa percepção da autora, na medida em que é referenciado na ideia de eficiência, de competitividade entre as diversas políticas que balizam as condicionalidades e na capacidade de esses programas operacionalizarem dois princípios operacionais que marcam essa nova geração de políticas: a descentralização participativa e a focalização. 
A descentralização participativa refere-se a um princípio operacional, que considera a ampliação do espectro de sujeitos envolvidos no processo de gestão das políticas públicas. De um lado, a sociedade é encarregada de controlar as ações do governo mediante a utilização de canais institucionalizados ou em construção no âmbito das lutas sociais. De outro lado, as instâncias governativas devem compartilhar esforços e informações para afinar e expandir a implementação das políticas, mas também para exercer controle direto sobre as ações desenvolvidas. Silva (2014 a, p.9) menciona, por exemplo, a ocorrência do procedimento fiscalista como medida de controle ao tratar das formas de pagamento identificadas no contexto dos PTRC: "transferências bancárias; dinheiro e cheque, cartões pré-pagos, bônus ou tickets e, em larga escala, cartões eletrônicos magnéticos, alguns com dispositivos sofisticados para controle do consumo de mercadorias".

Abrucio e Soares (2001, p. 26) entendem que a descentralização participativa apresenta três atributos fundamentais: democratização do poder local, aumento da eficácia e eficiência da gestão governamental; incentivo a inovações administrativas. No contexto dos PTRC, ações no sentido do privilegiamento da mulher como sujeito e uso de cartões magnéticos para a recepção dos benefícios podem ser consideradas inovações administrativas.

O repasse de recursos monetários aos beneficiários por meios magnéticos pode ser considerado, também, como uma forma positiva de gestão na medida em que reduz a intermediação de terceiros e a corrupção no sistema, o que tornaria o processo gestionário mais eficiente e eficaz. Não é possível, porém, comprovar que, de fato, se concretizam, nesse processo, os valores republicanos propalados: democratização do poder local e aumento do accountability, já que esses conceitos envolvem compromisso com uma ação pública responsável, transparente, voltada para prestação de contas exigidas por uma sociedade também preocupada com o cumprimento desses princípios.

O outro princípio que baliza os PTRC é da focalização. Justifica-se como uma maneira de evitar a dispersão recursos, direcionando-os para segmentos populacionais entendidos como vulneráveis posto que demandantes, comprovadamente situados nas faixas de renda previstas no contexto dos programas.

De acordo com Silva (2014a, p. 9), na focalização dos beneficiários dos PTRC analisados são utilizadas diferentes variáveis relacionados com esse princípio: "dimensionar e classificar a população em níveis ou linhas de pobreza, inclusive algumas com a construção de índices classificatórios, sendo a variável renda determinante na seleção dos beneficiários". Para sua concretização, no momento de operacionalização das ações de transferências, são firmadas parcerias com instituições como "bancos públicos ou privados credenciados; caixas móveis; redes de caixas automáticas ou terminais de autoatendimento, casas lotéricas, empresas transportadoras; pontos de pagamentos autorizados; agências de correios e a entidade executora".

A focalização é um procedimento que sofre críticas, de um lado, porque denuncia a própria incapacidade dos programas em alcançar todos os demandantes que compõem os próprios grupos alvo da política. De outro lado, esse princípio é atacado por razões de ordem ideopolítica, posto que considerado forma antagônica ao estatuto da universalidade. De fato, ao privilegiar o Estado enquanto instância mediadora dos interesses de alguns, a focalização formaria um contraponto à concepção republicana de Estado como instância capaz de avalizar o acesso, em condições de igualdade, para todos. Nesse sentido, a defesa da focalização como princípio das políticas públicas, como acontece com os PTRC, poderia se constituir em uma espécie de retorno aos conflitos primitivos, ao estado hobbesiano, a invalidação da relação necessária que se deve estabelecer entre políticas públicas e direitas sociais. Como lembra Oliveira (2007, p. 29) "quando se trata do capitalismo contemporâneo, então é o retorno à lei da força bruta". 


\section{Conclusão}

Os elementos expostos no presente documento apontam para os seguintes grupos de ponderações configurativas dos PTRC na América Latina e Caribe: O primeiro reforça a importância desses programas como lenitivo para a grande massa de despossuídos das condições materiais de existência. Considera-se, nesse caso, o imenso hiato identificável entre ricos e destituídos e os limites relacionados à captação e utilização do Fundo Público que se refletem na precarização estrutural do trabalho, da educação, da habitação, da saúde e outros campos relacionados à vida privada e coletiva.

Por outro lado, é preciso lembrar que muitas condições de vulnerabilidade e risco social que caracterizam a pobreza referenciada nos PTRC são originadas de processos relacionados à produção e reprodução do capitalismo que se refletem na vida social. Nesse contexto, situações vividas por extenso conjunto de trabalhadores acontecem a partir das clivagens da classe a que pertencem.

Dessa reflexão, deriva o segundo grupo de ponderações que balizam o texto. Nele, os PTCR são pensados como expressões de um momento particular do capitalismo em que o primado do público, da ética coletiva, da solidariedade na repartição social de riscos e benefícios vem sendo demolidos, dilatandose a lógica da competição e da racionalidade gerencial na operacionalização das políticas públicas. Tratase de um contexto em que demandas articuladas a direitos sociais são pensados como formas de ampliação crescente dos gastos públicos e os elos perdidos da política são tragados pelo princípio gestionário, que trata o social desvinculado do econômico e a política social como administração das urgências.

\section{Referências}

ABRUCIO, Fernando; SOARES, Márcia. Redes federativas no Brasil: Cooperação Intermunicipal no Grande A B C. São Paulo: Fundação Konrad Adenauer, 2001.

BOBBIO, Norberto. Estado, governo e sociedade: para uma teoria geral da política. Rio de Janeiro: Paz e Terra, 1992.

. A Era dos direitos. Rio de Janeiro: Campus/Elsevier, 1992a.

BOSCHETTI, Ivanete. Prefácio In: SILVA, Maria Ozanira da Silva e. Programas de Transferência de Renda na América Latina e Caribe. São Paulo: Cortez, 2014.

COUTO, Berenice Rojas, YAZBEK, Maria Carmelita, Silva, Maria Ozanira da Silva e RAICHELIS, Raquel (Orgs.). O Sistema Único de Assistência Social no Brasil: uma realidade em movimento. 4a ed. São Paulo: Cortez, 2014.

COUTO, Berenice Rojas, YAZBEK, Maria Carmelita e RAICHELIS, Raquel. (Orgs.). A Política Nacional de Assistência Social e o Suas: apresentando e problematizando fundamentos e conceitos. In: O Sistema Único de Assistência Social no Brasil: uma realidade em movimento. 4a ed. São Paulo: Cortez, 2014.

FLEURY, Sônia Maria. Estado sem cidadãos: seguridade social na América Latina. Rio de Janeiro: Fiocruz, 1994.

Seguridade Social: um novo patamar civilizatório. Disponível em: http://www12.senado.gov.br/publicacoes/estudoslegislativos/tipos-de-estudos/outras-publicacoes/volume-v-constituicao-de-1988-o-brasil-20-anos-depois.-os-cidadaos-na-cartacidada/seguridade-social-seguridade-social-um-novo-patamar-civilizatorio. Acesso em: 20/02/2015.

FOUCAULT, Michel. Microfísica do poder. 3a ed. Rio de Janeiro: Graal, 1982.

GIOVANNI, Geraldo. Sistema de proteção social: uma introdução conceitual. In: OLIVEIRA, Marcos Antônio de. Reforma do Estado e políticas de emprego no Brasil. Campinas: Unicamp, 1998.

HARVEY, D. O enigma do capital e as crises do capitalismo. São Paulo: Boitempo, 2011.

. Espaços da esperança. São Paulo: Loyola, 2004.

LIMA, Valéria, REIS, Carlos Nelson dos, ARREGUI, Carola e TRIPIANA, Jorge. Contextualização socioeconômica, política dos PTRC na América Latina e Caribe. In: SILVA, Maria Ozanira da Silva e (Coord.). Programas de Transferência de Renda na América Latina e Caribe. São Paulo: Cortez, 2014.

MARQUES, Rosa Maria. Políticas de transferência de renda no Brasil e na Argentina. Revista de Economia Política, v. 33, n. 2 (131), p. 298-314, abr./ jun. 2013.

OFFE, Claus. Problemas estruturais do estado capitalista. Rio de Janeiro: Tempo Brasileiro, 1984.

OLIVEIRA, Francisco. Política numa era de indeterminação: opacidade e reencantamento, In: OLIVEIRA, Francisco; RIZEK, Cibele Saliba (Orgs.). A era da indeterminação. São Paulo: Boitempo, 2007. 
PAOLI, Maria Célia. O mundo do indistinto: sobre gestão, violência e política. In: OLIVEIRA, Francisco; RIZEK, Cibele Saliba (Orgs.). A era da indeterminação. São Paulo: Boitempo, 2007.

PEREIRA, Potyara Amazoneida P. Porque também sou contra a focalização das Políticas Sociais. Disponível em: http://neppos.unb.br/publicacoes/contra focal.pdf. Acesso em: 15/02/2015.

POCHMANN, Márcio. Políticas de inclusão social: resultados e avaliação. São Paulo: Cortez, 2004.

SANTANA, R. N. Urbanidade e segregação: usos do território, modos segregados de moradia e imagens urbanas em são Luís, cidade patrimônio cultural da humanidade. In: LIMA, Antônia Jesuíta. Cidades Brasileiras: atores, processos e gestão pública. Belo Horizonte: Autêntica, 2007.

SANTANA, R. N.; SOUSA, S. M. P. S. Gestão pública da questão ambiental e tessituras das cidades brasileiras: notas preliminares. Revista Katálysis, Florianópolis, v .15, n. 1, p. 112-121, jan./jun. 2012.

SANTOS, Boaventura de Sousa (Org.). Democratizar a democracia: os caminhos da democracia participativa. Rio de Janeiro: Civilização Brasileira, 2002.

SILVA, Maria Ozanira. Caracterização e problematização dos programas de Transferência De Renda Na Condicionada (PTRC) na América Latina e Caribe In: Programas de Transferência de Renda na América Latina e Caribe. São Paulo: Cortez, 2014.

. Panorama Geral dos Programas de Transferência de Renda na América Latina e Caribe. Revista Políticas Públicas. São Luís, Número Especial, p. 299-306, jul. 2014a.

SOUSA, Salviana de M. P. S. A questão da democracia participativa na gestão do Planfor: qual democracia? Revista Katálysis, Florianópolis, v. 10, n. 2, jul./dez. 2007.

TELLES, Vera. Transitando na linha de sombra, tecendo as tramas da cidade (anotações inconclusas de uma pesquisa). In: OLIVERIA, Francisco; RIZEK, Cibele Saliba (Orgs.). A era da indeterminação. São Paulo: Boitempo, 2007.

VIANA, Ana Luiza D'Ávila; MACHADO, Cristiani Vieira. Proteção social em saúde: um balanço dos 20 anos do SUS. Physis - Revista de Saúde Coletiva, Rio de Janeiro, v.18 n. 4, p. 645-684, 2008.

VIANA, Maria Lúcia. Reforma do Estado e Políticas Sociais: nota à margem do tema. In: BEHERING, Elaine; ALMEIDA, Maria Helena. Trabalho e Seguridade Social: percursos e dilemas. São Paulo: Cortez, 2008.

\footnotetext{
${ }^{1}$ O projeto foi aprovado e financiado pela Coordenação de Aperfeiçoamento de Pessoal de Nível Superior - CAPES (Edital CGCI no. 072/2010) e pelo Conselho Nacional de Desenvolvimento Científico e Tecnológico - CNPq (Edital Universal - CNPq no. 14/2011).Participaram da pesquisa os Programas de Pós-Graduação em Políticas Públicas da Universidade Federal do Maranhão/Brasil; Programa de Pós-Graduação em Serviço Social da Pontifícia Universidade Católica de São Paulo/Brasil; Programa de Pós-Graduação em Serviço Social da Pontifícia Universidade Católica do Rio Grande do Sul/Brasil; Programa de Doctorado en Ciencias Sociales de la Faculdad de Ciencias Sociales de la Universidad de la Republica/Uruguay; Maestria em Ciencias Sociales de La Faculdad de Ciencias Humanas de La Universidad Nacional Del Centro de la Provincia de Buenos Aires da Argentina.

${ }^{2}$ Conferir, entre outros, Fleury (2010), Boschetti (2014), Giovanni (1998), Viana (2008).

${ }^{3} \mathrm{Na}$ América Latina e Caribe foram identificados, PTRC nos seguintes países; Honduras, Equador, Colômbia, Jamaica, México, Chile, Brasil, Peru, Paraguai, República Dominicana, Panamá, Costa Rica, Trindad e Tabago, Uruguai, Bolívia, El Salvador, Argentina e Guatemala (SILVA, 2014).

${ }^{4}$ Conferir Marques, 2013; Silva, 2014; Boschetti, 2014; Lima, Reis, Arregui e Tripiana (2014).

${ }^{5}$ Conjunto de 10 regras básicas elaboradas por instituições como FMI, Banco Mundial e o Departamento do Tesouro dos Estados Unidos em 1990 com o escopo de orientar o desenvolvimento econômico de países da América Latina e Caribe. Seguidas como substratos para obtenção de empréstimos, as regras do Consenso de Washington foram, posteriormente, acusadas por terem produzido crises e contribuído para aumentar a pobreza na região.

6 O aumento da pobreza no mundo instigou a elaboração de um de pacto materializado no documento denominado $A$ Declaração do Milénio das Nações Unidas. Essa foi aprovada na Cimeira do Milénio - realizada de 6 a 8 de Setembro de 2000, em Nova lorque. Expressa as preocupações de 147 Chefes de Estado e de Governo e de 191 países. Entre os propósitos definidos nesse documento destaca-se a redução, pela metade, da percentagem de pessoas que vivem na pobreza extrema. ${ }^{7}$ A medida mais difundida é a do Banco Mundial que, em seu Relatório de Desenvolvimento Mundial instituiu, em 1990 definiu que como medida de linha a pobreza mundial em menos de um dólar/ dia.

8 Viana (2008) faz referência aos programas de microcréditos que materializam o que denomina de empreendedorismo a Yunus: economista bengalês autor do livro "O banqueiro dos pobres".

${ }^{9}$ Sobre esse tema consultar Santana; Sousa (2012) e Offe (2004).
} 